\title{
High-Performance Core-Shell Catalyst with Nitride Nanoparticles as a Core: Well-Defined Titanium Copper Nitride Coated with an Atomic Pt Layer for the Oxygen Reduction Reaction
}

\author{
X. Tian, R. R. Adzic
}

Submitted to ACS Catalysis

June 2017

Chemistry Department

Brookhaven National Laboratory

\author{
U.S. Department of Energy \\ USDOE Office of Science (SC), \\ Basic Energy Sciences (BES) (SC-22)
}




\section{DISCLAIMER}

This report was prepared as an account of work sponsored by an agency of the United States Government. Neither the United States Government nor any agency thereof, nor any of their employees, nor any of their contractors, subcontractors, or their employees, makes any warranty, express or implied, or assumes any legal liability or responsibility for the accuracy, completeness, or any third party's use or the results of such use of any information, apparatus, product, or process disclosed, or represents that its use would not infringe privately owned rights. Reference herein to any specific commercial product, process, or service by trade name, trademark, manufacturer, or otherwise, does not necessarily constitute or imply its endorsement, recommendation, or favoring by the United States Government or any agency thereof or its contractors or subcontractors. The views and opinions of authors expressed herein do not necessarily state or reflect those of the United States Government or any agency thereof. 


\title{
High-Performance Core-Shell Catalyst with Nitride Nanoparticles as Core: Well-Defined Titanium Copper Nitride Coated with Atomic Pt Layer for Oxygen Reduction Reaction
}

Xinlong Tian ${ }^{1}$, Haibo Tang ${ }^{1}$, Junming Luo ${ }^{1}$, Haoxiong Nan ${ }^{1}$, Ting Shu, Li Du ${ }^{1}$, Jianhuang

Zeng $^{1}$, Shijun Liao ${ }^{1 *}$, and Radoslav R. Adzic ${ }^{2 *}$

1. The Key Laboratory of Fuel Cell Technology of Guangdong Province \& the Key

Laboratory of New Energy Technology of Guangdong Universities, School of Chemistry and

Chemical Engineering, South China University of Technology, Guangzhou 510641, China

2. Chemistry Department, Brookhaven National Laboratory, Upton, NY 11973, USA

\begin{abstract}
A class of core-shell low-platinum catalyst, with well-dispersed inexpensive titanium copper nitride nanoparticles as cores and atomic platinum layers as shells exhibiting high activity and stability for the oxygen reduction reaction (ORR) is successfully developed . Using nitrided carbon nanotubes (NCNTs) as the support greatly improved the morphology and dispersion of the nitride nanoparticles, resulting in significant enhancement of the catalyst’s performance. The optimized catalyst, $\mathrm{Ti}_{0.9} \mathrm{Cu}_{0.1} \mathrm{~N} @ \mathrm{Pt} / \mathrm{NCNTs}$, has a Pt mass activity five times higher than that of commercial Pt/C, comparable to that of core-shell catalysts with precious metal nanoparticles as the core and much higher than the latter if we take into account the mass activity of all platinum-group metals. Furthermore, only a minimal loss of activity is observable after 10,000 potential cycles, demonstrating the catalyst's high stability. Atomic-scale elemental mapping confirmed that the core-shell structure of the catalyst remained intact after durability testing. The approach may open a pathway to design
\end{abstract}


and prepare high performance inexpensive core-shell catalysts for a wide range of applications in energy-conversion processes.

Keywords: transition metal nitride, core-shell structure, stability, oxygen reduction reaction, fuel cells 


\section{Introduction}

Low-temperature proton exchange membrane fuel cells (PEMFCs) are of great interest for use in a wide variety of power applications due to their ability to convert chemical energy directly to electrical energy with high efficiency, high power density, low operating temperature, and low to zero emissions. ${ }^{1-2}$ While great progress has been made in PEMFCs in recent decades, several challenges continue to inhibit their large-scale deployment and commercialization, including the high cost, the sluggish kinetics of the oxygen reduction reaction (ORR), and their poor durability..$^{3-4}$ High cost is the key factor and is mainly due to the use of Pt as the catalyst at both the anode and the cathode. Thus, creating novel lowplatinum catalysts with low Pt loading, high Pt utilization, and corrosion resistance has become one of the most important issues in the field.

One way to boost the ORR activity of Pt-based catalysts is to construct PtM alloys $(\mathrm{M}=$ Fe, Co, Ni, Cu $)^{4-6}$ that have enhanced activity but use less Pt. However, such alloys typically suffer from insufficient stability because the less noble metal is continuously leached during electrochemical cycling in acidic conditions. ${ }^{7-8}$ Core-shell structured catalysts have attracted tremendous attention because they maximize the exposure of $\mathrm{Pt}$ atoms while minimizing $\mathrm{Pt}$ usage. ${ }^{9-10}$ In the past several years, various synthetic strategies have been developed for preparing Pt-based core-shell catalysts with various cores (e.g., Pd, Au, Ir, and Ru), based on underpotential deposition (UPD), ${ }^{11}$ seed-assistance, ${ }^{12}$ wet-chemical synthesis, ${ }^{13-15}$ or templating $^{16}$ techniques. The Pt mass activity of these catalysts has generally been significantly better than the conventional Pt/C catalyst, making the core-shell structure one of the most promising and attractive categories of low-platinum catalyst. Nevertheless, using noble metal nanoparticles (NPs) as the core eliminates the key advantage of high Pt mass activity offered by the core-shell structure. Generally, the content of the core in a core-shell catalyst is two or three times higher than that of the shell, so the cost of a precious-metal core 
is not negligible. Thus, exploring non-precious materials to use for the core is an urgent requirement in the development and practical application of core-shell structured catalysts.

Recently, we demonstrated a novel strategy to prepare a core-shell catalyst with nonprecious titanium nickel nitride (TiNiN) nanoparticles as the core and an ultra-thin Pt layer as the shell. ${ }^{17}$ The essential role of transition metal nitride NPs in achieving the core-shell structure makes our approach fundamentally distinct from others, and this core-shell catalyst with nitride NPs as the core not only sharply decreased the cost, but also demonstrated comparable ORR activity and durability to conventional core-shell catalysts with a precious metal as the core. However, a few disadvantages remain, such as larger particle size $(\sim 10 \mathrm{~nm})$ and insufficient particle dispersion. To further boost this novel nitride-based core-shell catalyst, we attempted to improve the dispersion of the nitride NPs and decrease the particle size by introducing NCNTs as the support. Through this strategy, we successfully prepared highly dispersed $\mathrm{Ti}_{0.9} \mathrm{Cu}_{0.1} \mathrm{~N}$ NPs with an average particle size of $\sim 5 \mathrm{~nm}$ and a well-defined morphology. We also prepared a new type of high-performance core-shell catalyst by depositing an ultra-thin Pt layer on the surface of our NCNT-supported binary nitride NPs. The catalyst exhibited significantly superior ORR performance compared to our previous nitride-based catalyst without NCNTs as the support. Our optimal catalyst, Ti ${ }_{0.9} \mathrm{Cu}_{0.1} \mathrm{~N} @ \mathrm{Pt} / \mathrm{NCNTs}$ (Pt: 7.8 wt\%), presented a Pt mass ORR activity five times higher than that of a commercial Pt/C catalyst, making it entirely comparable to a state-of-the-art $\mathrm{M} @ \mathrm{Pt} / \mathrm{C}$ catalyst with precious metal NPs as the core ${ }^{10,13-14,18-20}$ and placing it among the most efficient core-shell catalysts for the ORR reported to date (see Table S1 in the Supporting Information).

\section{Experimental Procedures}

2.1 Synthesis of TiN, TiCuN, TiN/NCNTs and TiMN/CNTs (M=Fe, Co, Ni, Cu)

All chemicals were purchased commercially (Aladdin, China) and were used without further purification. The CNTs (10-50 nm in diameter and 30-50 microns in length) were 
treated with $\mathrm{H}_{2} \mathrm{SO}_{4} / \mathrm{HNO}_{3}\left(3: 1\right.$ volume ratio) in an ultrasonic bath at $60^{\circ} \mathrm{C}$ for 8 hours, followed by filtration and thorough washing with deionized water. In the next stage, $20 \mathrm{mg}$ pretreated and dried CNTs were dispersed in $50 \mathrm{~mL}$ ethanol (absolute grade) under stirring, then titanium tetrachloride $\left(\mathrm{TiCl}_{4}, 10 \mu \mathrm{L}\right)$ and dehydrated cupric acetate monohydrate $\left(\mathrm{Cu}\left(\mathrm{CH}_{3} \mathrm{COO}\right)_{2}, 1.82 \mathrm{mg}\right)$ were added to the CNT suspension, and the mixture was continuously stirred for $2 \mathrm{~h}$, maintaining a 9:1 atomic ratio of $\mathrm{Ti}$ to $\mathrm{Cu}$. Then $\mathrm{NH}_{3}$ was introduced into the mixture with continuous stirring for 30 min to obtain an ammonia complex of $\mathrm{Ti}$ and $\mathrm{Cu}$. After evaporation of the solvent in a vacuum drying oven at $70^{\circ} \mathrm{C}$ overnight, the powdered precursor was placed in a tubular furnace and annealed at $700^{\circ} \mathrm{C}$ under an $\mathrm{NH}_{3}$ gas flow (50 sccm) for $2 \mathrm{~h}$ with progressive heating rates (room temperature to $680^{\circ} \mathrm{C}, \quad 5^{\circ} \mathrm{C} \min ^{-1} ; \quad 680^{\circ} \mathrm{C}$ to $700^{\circ} \mathrm{C}, 1^{\circ} \mathrm{C} \min ^{-1}$ ). We denote this product as $\mathrm{Ti}_{0.9} \mathrm{Cu}_{0.1} \mathrm{~N} / \mathrm{NCNTs}$. For comparison, TiN/NCNTs was prepared using the same procedures as described as above but without the addition of $\mathrm{Cu}\left(\mathrm{CH}_{3} \mathrm{COO}\right)_{2}$. For the synthesisi of TiMN/CNTs (M=Fe, Co, $\mathrm{Ni}), \mathrm{Fe}\left(\mathrm{CH}_{3} \mathrm{COO}\right)_{2}, \mathrm{Co}\left(\mathrm{CH}_{3} \mathrm{COO}\right)_{2}$, and $\mathrm{Ni}\left(\mathrm{CH}_{3} \mathrm{COO}\right)_{2}$ was added, respectively, instead of $\mathrm{Cu}\left(\mathrm{CH}_{3} \mathrm{COO}\right)_{2}$. We also prepared unsupported TiN and TiCuN NPs using the above procedures but without the addition of CNTs. For the sample of as-prepared TiN@Pt/NCNTs, the weight ratio of TiN and NCNT is 20.2 wt $\%$, while for $\mathrm{Ti}_{0.9} \mathrm{Cu}_{0.1} \mathrm{~N} @ \mathrm{Pt} / \mathrm{NCNTs}$, the ratio value is $20.6 \mathrm{wt} \%$ for $\mathrm{Ti}_{0.9} \mathrm{Cu}_{0.1} \mathrm{~N}$.

2.2 Synthesis of TiN@Pt, TiCuN@Pt, TiN@Pt/NCNTs and TiMN@Pt/CNTs (M=Fe, Co, Ni, $\mathrm{Cu})$

An ultra-thin Pt layer was deposited on the TiN/NCNTs and TiCuN/NCNTs NPs using a pulse electrodeposition (PED) approach previously described by our group ${ }^{21-23}$. Briefly, $5 \mathrm{mg}$ of the support was put into $1 \mathrm{~mL}$ Nafion/ethanol (0.25 wt\% Nafion) solution through ultrasonic dispersion to form a slurry, and $4 \mu \mathrm{L}$ of this slurry was pipetted onto a glassy carbon surface ( $5 \mathrm{~mm}$ inner diameter, $0.196 \mathrm{~cm}^{2}$ ) to function as a substrate for deposition. An electrolyte solution containing $\mathrm{H}_{2} \mathrm{PtCl}_{6} \cdot 6 \mathrm{H}_{2} \mathrm{O}$ (5 mmol), polyvinylpyrrolidone (PVP, 50 
mmol), $0.1 \mathrm{M} \mathrm{Na}_{2} \mathrm{SO}_{4}$, and $0.4 \mathrm{M} \mathrm{H}_{2} \mathrm{SO}_{4}$ was used for the deposition, with $\mathrm{T}_{\text {on }}$ (time of connection) $3 \mathrm{~ms}$ and $\mathrm{T}_{\text {off }}$ (time of disconnection) $30 \mathrm{~ms}$. The deposited amount of $\mathrm{Pt}(\mathrm{Pt}$ loading) could be tuned by varying the deposition cycles, and the actual Pt loading was determined by inductively coupled plasma optical emission spectrometry (ICP-OES, Leeman PROFILE SPEC) analysis. The prepared electrodes were used directly for the electrochemical measurements without any further treatment.

2.3 Physical characterization of the catalysts

X-ray diffraction (XRD) was conducted on a TD-3500 powder diffractometer (Tongda, China) at $30 \mathrm{kV}$ and $20 \mathrm{~mA}$ with $\mathrm{Cu} \mathrm{K} \alpha$ radiation $(\lambda=1.5405 \AA)$ in the Bragg angle range of $20^{\circ}$ to $86^{\circ}$. Scanning electron microscopy (SEM) and energy-dispersive X-ray analysis (EDX) were performed with a field-emission scanning electron microscope (FESEM, Hitachi S4800). Transmission electron microscopy (TEM) and high-resolution transmission electron microscopy (HRTEM) images were acquired with a JEOL 2100 microscope. X-ray photoelectron spectroscopy (XPS) was performed on an Axis Ultra DLD X-ray photoelectron spectrometer employing a monochromated Al-Ka X-ray source $(\mathrm{hv}=1486.6 \mathrm{eV})$. High-angle annular dark field (HAADF) imaging and energy-dispersive spectrometer (EDS) elemental mapping analysis were performed in the scanning transmission electron microscopy (STEM) mode on an aberration-corrected FEI Titan G2 60-300 field-emission TEM, operated at 300 $\mathrm{kV}\left(\alpha_{\max }=\sim 100 \mathrm{mrad}\right)$. Under these experimental conditions, the image contrast was directly related to the atomic number (Z-contrast).

\subsection{Electrochemical measurements}

All electrochemical experiments were carried out on an electrochemical work station (Ivium, Netherlands) at room temperature $\left(25 \pm 1^{\circ} \mathrm{C}\right)$, using a three-electrode electrochemical cell. The cell consisted of a glassy carbon working electrode (5 mm inner diameter, 0.196 $\mathrm{cm}^{2}$ ), a platinum-foil counter electrode, and an $\mathrm{Ag} / \mathrm{AgCl}(3 \mathrm{M} \mathrm{NaCl})$ reference electrode. All potentials in this work were corrected with respect to a reversible hydrogen electrode (RHE). 
The catalyst electrode was prepared as described in section 2.2. For comparison, a commercial JM Pt/C (Johnson Matthey, 2-5 nm, 20 wt \% Pt supported on Vulcan XC-72R carbon, the Pt loading on the RDE was $8.78 \mu \mathrm{gcm}^{-2}$ ) electrode was prepared as the followings: First, a catalyst ink was prepared by ultrasonicating a mixture of $5.0 \mathrm{mg}$ of $\mathrm{Pt} / \mathrm{C}$ and 1 $\mathrm{mL}$ of Nafion ( $0.25 \mathrm{wt} \%$ ) ethanol solution for $30 \mathrm{~min}$. Subsequently, $1.72 \mu \mathrm{L}$ of catalyst ink was pipetted onto the GCE surface, and the GCE was dried under an infrared lamp for 5 min.

Static cyclic voltammetry (CV) characterization of the catalysts was typically carried out in $\mathrm{N}_{2}$-saturated $0.1 \mathrm{M} \mathrm{HClO}_{4}$ solution, in a potential range from 0 to $1.2 \mathrm{~V}$ at a scan rate of $50 \mathrm{mVs}^{-1}$. ORR measurements were carried out in $\mathrm{O}_{2}$-saturated $0.1 \mathrm{M} \mathrm{HClO}_{4}$ electrolyte, using a rotation rate of $1600 \mathrm{rpm}$ and a scan rate of $10 \mathrm{mVs}^{-1}$. Before the ORR activity test, all the electrodes were pretreated by cycling the potential between 0 and $1.2 \mathrm{~V}$ at a sweep rate of $50 \mathrm{mVs}^{-1}$ for 20 cycles to remove any surface contaminants. We calculated the specific electrochemical active surface area (ECSA) of each catalyst on the basis of the charges associated with the desorption of hydrogen after double-layer correction with a reference value of $210 \mu \mathrm{Ccm}^{-2}$ for the desorption of a monolayer of hydrogen from a Pt surface. Accelerated durability testing (ADT) was performed in $\mathrm{O}_{2}$-saturated $0.1 \mathrm{M} \mathrm{HClO}_{4}$ in the potential range from 0.6 to $1.05 \mathrm{~V}$ at room temperature. The kinetic current was calculated from the ORR polarization curves $(0.9 \mathrm{~V})$ by using the Koutecky-Levich equation: $1 / \mathrm{i}=1 / \mathrm{i}_{\mathrm{k}}$ $+1 / i_{d}$ (where $i_{d}$ is the diffusion-limiting current and $i_{k}$ is the kinetic current). To calculate the mass activity and specific activity, the kinetic current was normalized to the actual Pt loading and the ECSA of the catalyst, respectively.

\section{Results and Discussion}

The supported nitride NPs were prepared by synthesizing oxide nanoparticles on carbon nanotubes using a facile hydrothermal process. The oxide and the support were then nitrided in an ammonia atmosphere. Figure 1 shows the XRD patterns of the as-prepared TiN/NCNTs, $\mathrm{Ti}_{0.9} \mathrm{Cu}_{0.1} \mathrm{~N} / \mathrm{NCNTs}$, and $\mathrm{Ti}_{0.9} \mathrm{Cu}_{0.1} \mathrm{~N} @ \mathrm{Pt} / \mathrm{NCNTs}$ samples. The TiN/NCNTs and 
$\mathrm{Ti}_{0.9} \mathrm{Cu}_{0.1} \mathrm{~N} / \mathrm{NCNTs}$ samples clearly showed almost the same XRD peaks, which correspond to the face-centered cubic (fcc) structure of TiN (JCPDS No. 38-1420). The estimated diameters of typical $\mathrm{TiN}$ or $\mathrm{Ti}_{0.9} \mathrm{Cu}_{0.1} \mathrm{~N}$ nanoparticles are 5.1 and $4.9 \mathrm{~nm}$, respectively, compared with the $10 \mathrm{~nm}$ of nitride NPs without CNTs support; hence, the introduction of the support markedly decreased the particle size. ${ }^{17,24}$ No peaks corresponding to copper or copper nitride were observable, demonstrating that the copper was well incorporated into the lattice of the TiN. According to the SEM-EDX and ICP-OES results (Table S2, Supporting Information), the measured composition of $\mathrm{Ti}_{0.9} \mathrm{Cu}_{0.1} \mathrm{~N} @ \mathrm{Pt} / \mathrm{NCNTs}(\mathrm{Ti} / \mathrm{Cu}=9.12: 1)$ is very close to its recipe composition, indicating that the chemical composition could be modulated by tuning the feeding ratio of the metal precursors in the synthesis process. After Pt deposition, a very weak diffraction peak belonging to Pt was observable for the samples with $7.8 \mathrm{wt} \%$ Pt, indicating the successful deposition of Pt on the nitride NPs.
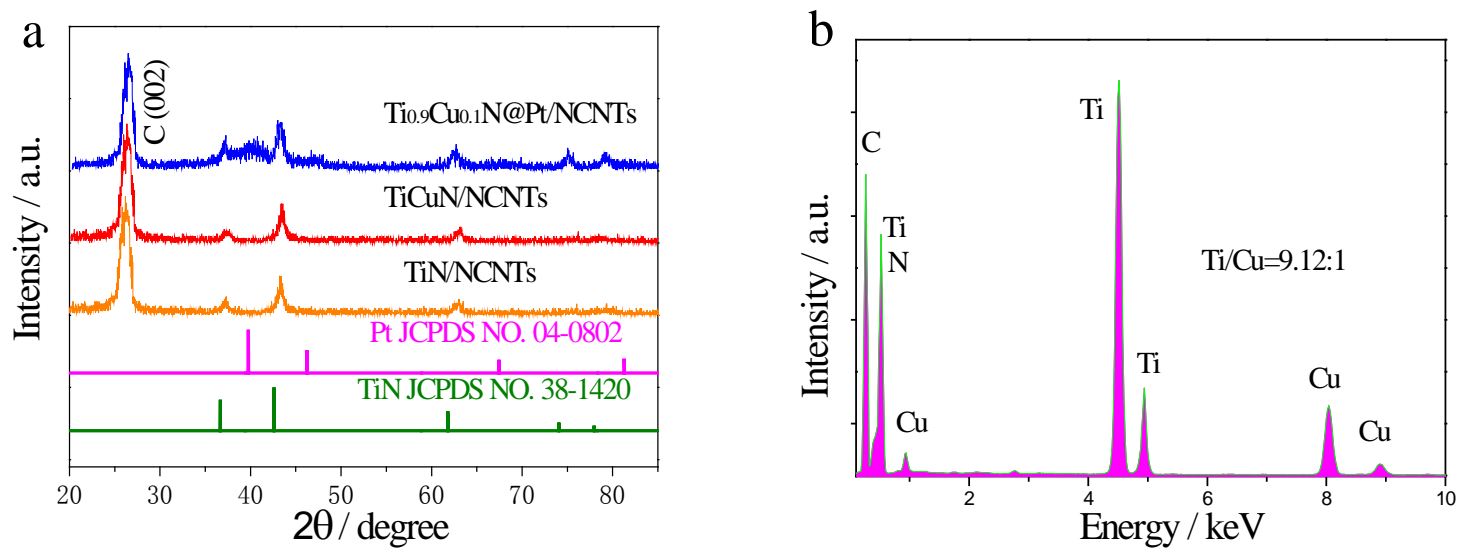

Figure 1. (a) XRD patterns of as-prepared TiN/NCNTs, $\mathrm{Ti}_{0.9} \mathrm{Cu}_{0.1} \mathrm{~N} / \mathrm{NCNTs}$, and $\mathrm{Ti}_{0.9} \mathrm{Cu}_{0.1} \mathrm{~N} @ \mathrm{Pt} / \mathrm{NCNTs}$, and (b) SEM-EDX profile of $\mathrm{Ti}_{0.9} \mathrm{Cu}_{0.1} \mathrm{~N} / \mathrm{NCNTs}$ sample.

TEM and SEM images (Figure 2 and Figure S1) clearly show that the nitride NPs were well dispersed on the NCNTs and exhibited an average size of $\sim 5 \mathrm{~nm}$. The selected area electron diffraction (SAED) patterns of the hybrid materials show a series of well-defined rings, which can be assigned to various diffraction planes of (fcc) TiN. Meanwhile, the lattice 
fringes of the supported NPs, determined by HRTEM $(0.251 \mathrm{~nm})$, were consistent with the (111) plane of the TiN crystal structure (insets of Figure 2a and b). ${ }^{25-26}$ No obvious morphological changes and no Pt NPs were observable from the TEM images of the TiN@Pt/NCNTs and $\mathrm{Ti}_{0.9} \mathrm{Cu}_{0.1} \mathrm{~N} @ P t / \mathrm{NCNTs}$ materials after Pt deposition (Figure 2c and d). However, the lattice spacing of Pt (111) $(0.227 \mathrm{~nm})^{1}$ is clearly visible in the magnified HRTEM images, verifying the existence of Pt on the surface of the supported nitride NPs (insets of Figure 2c and d). The STEM/EDS mapping images clearly reveal the deposition of a Pt layer on the nitride nanoparticles, or the core-shell structure of $\mathrm{Ti}_{0.9} \mathrm{Cu}_{0.1} \mathrm{~N} @ \mathrm{Pt} / \mathrm{NCNTs}$, as shown in Figure 2e-j. All four elements distributed within the particle area, revealing their existence and uniform distribution. Conversely, the distribution area of Pt was slightly larger, and it exhibited a higher intensity at the rim and a lower intensity in the central area (Figure 2j). Additionally, the overlapping image (Figure 2f) of the four elements shows a clear contrast between the Pt shell (green) and the core (mainly Ti, red), further demonstrating the formation of the core-shell structure. 


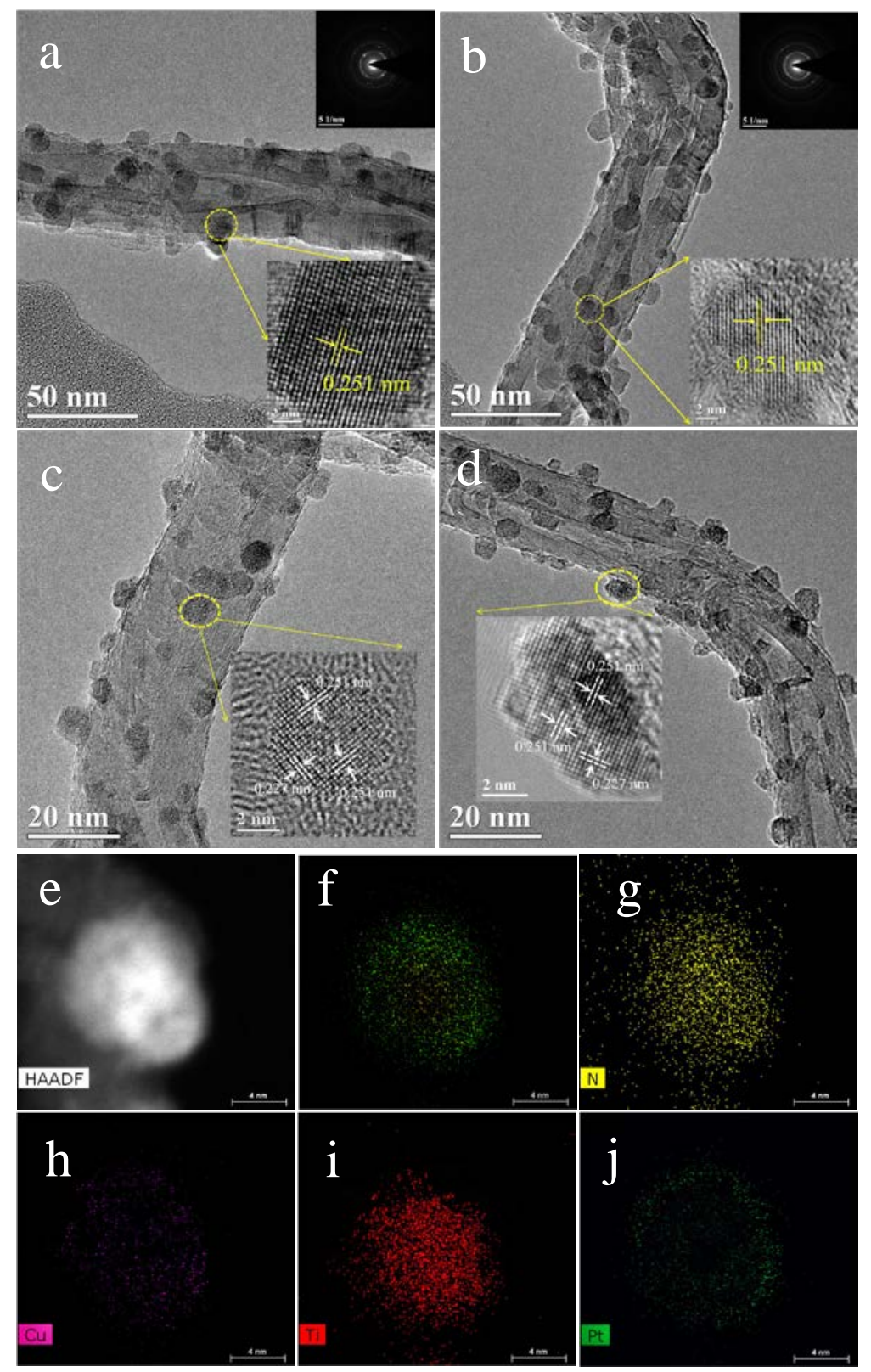

Figure 2. TEM images of (a) TiN/NCNTs, (b) Ti ${ }_{0.9} \mathrm{Cu}_{0.1} \mathrm{~N} / \mathrm{NCNTs}$, (c) TiN@Pt/NCNTs, and (d) $\mathrm{Ti}_{0.9} \mathrm{Cu}_{0.1} \mathrm{~N} @ \mathrm{Pt} / \mathrm{NCNTs}$, with a Pt loading of $7.8 \mathrm{wt} \%$, and the inserts are the corresponding HRTEM and SAED images. (e) HAADF/STEM image of a single nanoparticle of $\mathrm{Ti}_{0.9} \mathrm{Cu}_{0.1} \mathrm{~N} @ \mathrm{Pt} / \mathrm{NCNTs}$ catalyst. (f) Overlapping elemental maps of Pt, N, Cu, and Ti. EDS elemental mapping images of (g) N, (h) Cu, (i) Ti, and (j) Pt. Bar sizes: 4 nm.

Figure 3a shows the CV curves of Pt/C, TiN@Pt/NCNTs, and Ti ${ }_{0.9} \mathrm{Cu}_{0.1} \mathrm{~N} @ P t / \mathrm{NCNTs}$ in nitrogen-saturated $0.1 \quad \mathrm{M} \mathrm{HClO} 4$ solution. From these curves, we calculated the electrochemical surface areas (ECSAs) of the TiN@Pt/NCNTs and $\mathrm{Ti}_{0.9} \mathrm{Cu}_{0.1} \mathrm{~N} @ \mathrm{Pt} / \mathrm{NCNTs}$ 
samples to be 104.5 and $100.2 \mathrm{~m}^{2} \mathrm{~g}^{-1}$, respectively; these were almost twice that of $\mathrm{JM} \mathrm{Pt} / \mathrm{C}$ (55.6 $\left.\mathrm{m}^{2} \mathrm{~g}^{-1}\right)$. Of course, the larger ECSA should be a result of the higher dispersion of Pt in the ultra-thin shell layer. As depicted in Figure 3b, both the TiN@Pt/NCNTs and the $\mathrm{Ti}_{0.9} \mathrm{Cu}_{0.1} \mathrm{~N} @ \mathrm{Pt} / \mathrm{NCNTs}$ exhibited much higher ORR catalytic activities than JM Pt/C when almost the same Pt loadings were kept on the electrodes; in addition, doping with a second transition metal, $\mathrm{Cu}$, significantly enhanced the catalyst's ORR activity. In fact, the higher onset potential of $\mathrm{Ti}_{0.9} \mathrm{Cu}_{0.1} \mathrm{~N} @ \mathrm{Pt} / \mathrm{NCNTs}$ than of either TiN@Pt/NCNTs or Pt/C, as well as its Tafel plots (Figure 3c), also confirmed the substantially higher activity of $\mathrm{Ti}_{0.9} \mathrm{Cu}_{0.1} \mathrm{~N} @ \mathrm{Pt} / \mathrm{NCNTs}$, further revealing the significant improvement caused by Cu doping, which will be discussed later. The Pt mass activity and specific activity of $\mathrm{Ti}_{0.9} \mathrm{Cu}_{0.1} \mathrm{~N} @ \mathrm{Pt} / \mathrm{NCNTs}$ at $0.9 \mathrm{~V}$ reached $1.06 \mathrm{~A} \mathrm{mg}_{\mathrm{Pt}}^{-1}$ and $0.69 \mathrm{~mA} \mathrm{~cm}{ }^{-2}$, respectively, which were around five and 3.3 times higher than that of JM Pt/C (Figure 3d). In addition, using the slopes of $\mathrm{K}-\mathrm{L}$ plots, we calculated the electron transfer number of $\mathrm{Ti}_{0.9} \mathrm{Cu}_{0.1} \mathrm{~N} @ \mathrm{Pt} / \mathrm{NCNTs}$ for catalyzing the ORR to be roughly 3.9, demonstrating its high selectivity for the four-electron transfer path (Figure S2).

Compared with our previously reported TiNiN@Pt ${ }^{17}$ catalyst without nitride CNTs as the support, the mass activity of $\mathrm{Ti}_{0.9} \mathrm{Cu}_{0.1} \mathrm{~N} @ \mathrm{Pt} / \mathrm{NCNTs}$ was enhanced by ca. 25\%, indicating the significant improvement caused by the introduction of NCNTs as the support. Furthermore, the Pt mass activity of our $\mathrm{Ti}_{0.9} \mathrm{Cu}_{0.1} \mathrm{~N} @ \mathrm{Pt} / \mathrm{NCNTs}$ is ca. 20\% higher than those of the state-of-the-art $\mathrm{M} @ P t$ nanocatalysts $\left(\mathrm{M}=\mathrm{Pd},{ }^{9-10,13-14,16} \mathrm{Ru},{ }^{20,27-28}\right.$ and $\left.\mathrm{Au}^{19,29}\right)$. If we take into account the mass activity of all the precious metals, the activity of our catalyst is 2 to 4 times higher than that of the catalyst with precious metals as cores (Table S1). In other words, using highly dispersed nitride NPs as the core instead of precious metal NPs will decrease the cost of the catalyst several fold, because the cost of a nitride core is negligible compared with that of a precious metal core. The mass activity of $\mathrm{Ti}_{0.9} \mathrm{Cu}_{0.1} \mathrm{~N} @ \mathrm{Pt} / \mathrm{NCNTs}$ is even comparable to the values for very recently reported Pt shell-based nanoframes or 
nanocages, ${ }^{2,30-31}$ further emphasizing the multiple catalysis enhancement effects derived from having a nitride NPs-based core-shell structure.
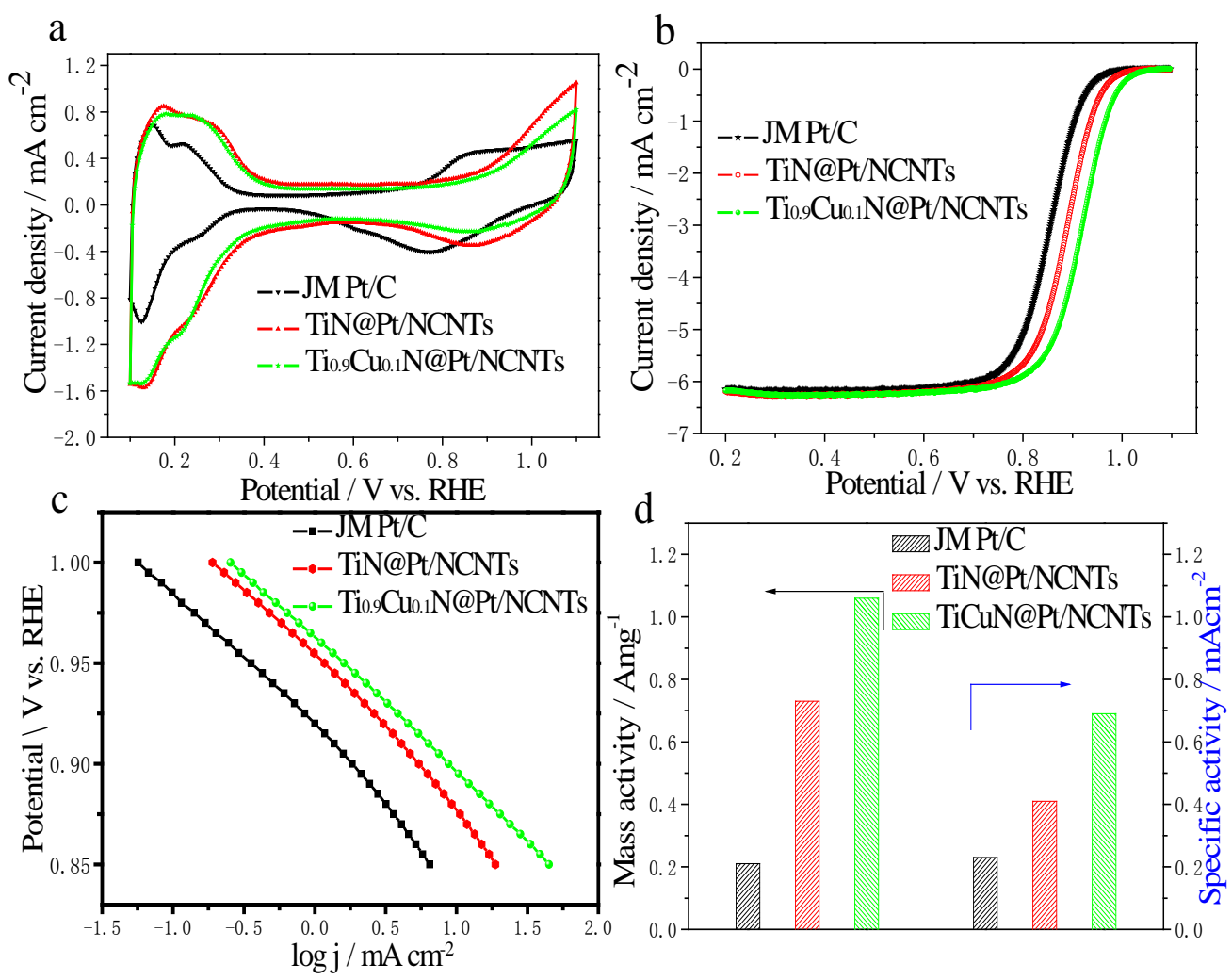

Figure 3. (a) The CV curves of JM Pt/C, TiN@Pt/NCNTs, and Ti ${ }_{0.9} \mathrm{Cu}_{0.1} \mathrm{~N} @ P t / N C N T s$ with Pt loadings of 8.78, 8.63, and $8.58 \mu \mathrm{g} \mathrm{cm}^{-2}$, respectively. (b) The polarization curves of Pt/C, TiN@Pt/NCNTs, and Ti ${ }_{0.9} \mathrm{Cu}_{0.1} \mathrm{~N} @ P t / \mathrm{NCNTs}$ in $\mathrm{O}_{2}$-saturated 0.1 M HClO${ }_{4}$ solution, using a RDE at $1600 \mathrm{rpm}$ and a scan rate of $10 \mathrm{mVs}^{-1}$. (c) The corresponding Tafel plots and (d) the mass activity and specific activity of Pt/C, TiN@Pt/NCNTs, and $\mathrm{Ti}_{0.9} \mathrm{Cu}_{0.1} \mathrm{~N} @ \mathrm{Pt} / \mathrm{NCNTs}$.

It was found that doping with a second transition metal in the nitride core could significantly enhance the activity of the final platinum-deposited catalyst. ${ }^{32-33}$ We investigated the effects of $\mathrm{Fe}$, $\mathrm{Co}, \mathrm{Ni}$ and $\mathrm{Cu}$, and found that the $\mathrm{Cu}$ doping yielded the best results, with the optimal ratio of $\mathrm{Ti} / \mathrm{Cu}$ being 9:1 (Figure S3). In the same doping concentration, the $\mathrm{Cu}$ doping, yielded the greatest improvement in performance for our core-shell structured 
TMN@Pt/NCNTs system, which may be due to the higher donation capacity of $\mathrm{Cu}$ atom compared with other transition metals investigated, since $\mathrm{Cu}$ atom exhibits 10 electrons in the d-bond. The Pt mass activity of the $\mathrm{Ti}_{0.9} \mathrm{Cu}_{0.1} \mathrm{~N} @ \mathrm{Pt} / \mathrm{NCNTs}$ catalyst was enhanced by $40 \%$ compared to a catalyst without $\mathrm{Cu}$ doping. To verify the importance of nitride NPs as the core, we tried depositing Pt on NCNTs using the same procedures as we had used for the $\mathrm{Ti}_{0.9} \mathrm{Cu}_{0.1} \mathrm{~N} / \mathrm{NCNTs}$. The prepared sample, NCNTs@Pt, exhibited almost the same ORR activity as the one with NCNTs alone, and TEM revealed only a few large Pt particles on the surface of the NCNTs (Figure S4).

It is worth noting that in an acidic medium, the ORR activity of NCNTs alone or of transition metal nitrides alone is negligible compared with that of a Pt-based catalyst, as shown in Figure S5. To understand the strong positive effect of $\mathrm{Cu}$ doping on the catalyst's performance, we analyzed the samples using XPS. The binding energies of Pt $4 \mathrm{f}_{7 / 2}$ and $\mathrm{Pt} 4 \mathrm{f}_{5 / 2}$ were 70.80 and $74.03 \mathrm{eV}$ for $\mathrm{Ti}_{0.9} \mathrm{Cu}_{0.1} \mathrm{~N} @ \mathrm{Pt} / \mathrm{NCNTs}$ and 71.19 and $74.46 \mathrm{eV}$ for TiN@Pt/NCNTs (Figure 4a and Table S5). Clearly, there was a significant negative shift of ca. $0.40 \mathrm{eV}$ with $\mathrm{Cu}$ doping, indicating that it enhanced electron donation from the nitride core to the Pt shell. Many researchers have shown that the strong interaction between pure Pt and intermediate oxide species (mainly $\mathrm{OH}$ ) formed during oxygen reduction is one of the key reasons for the unfavorable ORR performance of Pt catalysts. ${ }^{33-36}$ The strong interaction makes it's very difficult to remove $\mathrm{OH}$ groups from the surface of these catalysts, so the ORR activity was weakened. It has also been found that proper alloying/doping can lead to the decrease in the d-band vacancy of Pt (Pt is more electron rich), which is beneficial for weakening the interaction and removal of $\mathrm{OH}$ groups. ${ }^{37}$ To achieve a desirable ORR performance, the surface of the catalyst should exhibit the optimum balance between the kinetics of $\mathrm{O}-\mathrm{O}$ bonding breaking $\left(\mathrm{O}_{2}\right.$ adsorption) and the electroreduction of the oxygenated intermediates (intermediate oxide species dissociation/removal). ${ }^{34-35,37-38}$ In this work, we found that the incorporation of $\mathrm{Cu}$ in the nitride core could result in a negative shift in the 
binding energy of Pt by $0.4 \mathrm{~V}$, demonstrating that Pt atoms could obtain electrons as a result of $\mathrm{Cu}$ doping. Thus, a lower adsorption strength of oxygen intermediate species on the Pt atoms and easier removal of adsorbed $\mathrm{OH}$ groups from the surface of the $\mathrm{Ti}_{0.9} \mathrm{Ni}_{0.1} \mathrm{~N} @ \mathrm{Pt} / \mathrm{NCNTs}$ catalyst, so the ORR activity was improved. ${ }^{34,37,39}$ On the other hand, the lattice parameter changes of Pt were investigated by sophisticated XRD measurement for the three catalysts: Pt/C, TiN@Pt/NCNTs and Ti ${ }_{0.9} \mathrm{Cu}_{0.1} \mathrm{~N} @ P t / N C N T s$ (Figure S6). As can be seen, the Pt(111) peaks of TiN@Pt/NCNTs were significantly shifted to the higher angles compared with Pt/C catalyst (Figure S6a), and this phenomenon appears to be even greater when $\mathrm{Cu}$ element was incorporated to the TiN nanostructure, suggesting the decrease of Pt(111) lattice spacing. For the samples of TiN@Pt/NCNTs and $\mathrm{Ti}_{0.9} \mathrm{Cu}_{0.1} \mathrm{~N} @ \mathrm{Pt} / \mathrm{NCNTs}$, compressive strain, roughly $-3.08 \%$ and $-3.96 \%$, respectively, were obtained due to the deposition of $\mathrm{Pt}$ atoms on $\mathrm{Ti}$ atoms, which exhibits a smaller atomic radius, resulting in a reduced Pt-Pt interatomic distance in the Pt shell (Figure S6b). According to the previous reports $^{35,38,40}$, compressive strain would be induced when Pt layers were deposited on other metals that the atomic radius is smaller than that of Pt, and the ORR activity can be further enhanced.

Figure 4b shows the XPS spectra of N1s for NCNTs, TiN/NCNTs, and $\mathrm{Ti}_{0.9} \mathrm{Cu}_{0.1} \mathrm{~N} / \mathrm{NCNTs}$. Compared with TiN without the support $(397.3 \mathrm{eV})^{24}$, the N-Ti binding energy of TiN/NCNTs and $\mathrm{Ti}_{0.9} \mathrm{Cu}_{0.1} \mathrm{~N} / \mathrm{NCNTs}$ shifted positively by $0.3 \mathrm{eV}$, demonstrating an interaction between the metal nitride and the NCNTs. The formation of C-Ti bonds (Figure S7) also indicated intimate couplings between the nitride NPs and the NCNTs, allowing for rapid electron transfer from active materials to current collectors during the ORR process. Interestingly, the TiN/NCNTs and $\mathrm{Ti}_{0.9} \mathrm{Cu}_{0.1} \mathrm{~N} / \mathrm{NCNTs}$ exhibited almost the same N-Ti binding energies, so it seems that the $\mathrm{Cu}$ doping did not affect the Ti-N bond. However, the $\mathrm{Cu}$ doping significantly affected the Ti $2 \mathrm{p}$ bond, which shifted negatively by $0.27 \mathrm{eV}$ after $\mathrm{Cu}$ doping (Figure 4c). As shown in Figure 4c, the XPS results confirmed the existence of N-C 
bonds, implying that the CNTs had been successfully nitrided during the nitriding process. In addition, the fraction of pyridinic $\mathrm{N}$ in the NCNTs sample (398.6 eV) was quite different from the fractions in the TiN/NCNTs and $\mathrm{Ti}_{0.9} \mathrm{Cu}_{0.1} \mathrm{~N} / \mathrm{NCNTs}$ samples. Pyridinic $\mathrm{N}$ was the leading $\mathrm{N}$ species in the former, whereas pyrrolic $\mathrm{N}(400.2 \mathrm{eV})$ was the major species in the latter two ${ }^{41-42}$, revealing that the presence of a transition metal nitride may affect the $\mathrm{N}$ doping of CNTs. Based on the above information, we suggest that the outstanding ORR performance of our catalyst is attributable not only to the ultrathin Pt shell layer, but also to the high dispersion of nitride NPs, the enhanced conductivity caused by the introduction of NCNTs as the support, and the synergistic effects composed of both the ligand effect and strain effect due to the Cu doping.
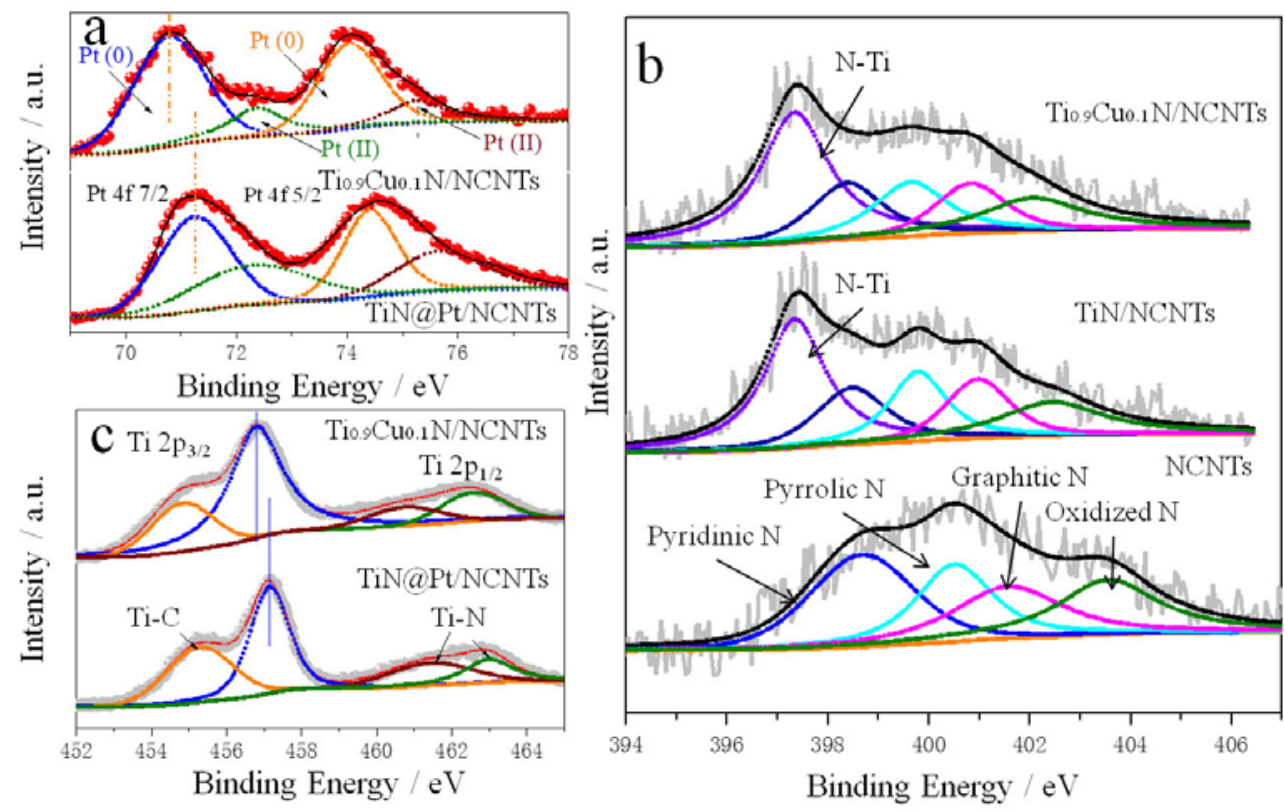

Figure 4. (a) The high-resolution XPS spectra of Pt 4f. (b) The N1s spectra of TiN/NCNTs, $\mathrm{Ti}_{0.9} \mathrm{Cu}_{0.1} \mathrm{~N} / \mathrm{NCNTs}$, and NCNTs. (c) The Ti 2p spectra of TiN/NCNTs and $\mathrm{Ti}_{0.9} \mathrm{Cu}_{0.1} \mathrm{~N} / \mathrm{NCNTs}$.

It is interesting that the catalyst exhibited extremely high stability. The ECSA calculated from the hydrogen underpotential desorption (HUPD) peak for JM Pt/C catalyst dropped by ca. 50\% (Figure 5a and b) after 10,000 CV cycles. However, for the $\mathrm{Ti}_{0.9} \mathrm{Cu}_{0.1} \mathrm{~N} @ \mathrm{Pt} / \mathrm{NCNTs}$ 
catalyst, almost no change was observable after 10,000 cycles. Furthermore, a $26 \mathrm{mV}$ negative shift in the half-wave potential was observed for the Pt/C catalyst after the stability test, compared to only $5 \mathrm{mV}$ for $\mathrm{Ti}_{0.9} \mathrm{Cu}_{0.1} \mathrm{~N} @ \mathrm{Pt} / \mathrm{NCNTs}$ (Figure 5c), revealing the outstanding stability of our nitride-based catalysts. Furthermore, TiN@Pt/NCNTs was also much more stable than JM Pt/C (Figure S8). What caused such high stability? We suggest that the Pt-nitride interaction may be stronger than the interaction between $\mathrm{Pt}$ and carbon, resulting in a strong bond and altering the electronic structure of the surface Pt atoms, thereby creating a stabilizing effect against Pt oxidation/dissolution. This suggestion is supported by the fact that Pt oxidation was highly suppressed at high potential ${ }^{43-44}$, as indicated by the CV curves for $\mathrm{Ti}_{0.9} \mathrm{Cu}_{0.1} \mathrm{~N} @ \mathrm{Pt} / \mathrm{NCNTs}$, TiN@Pt/NCNTs, and Pt/C (Figure 3a). Oxidation suppression (i.e., a lower amount of Pt oxidation) has the potential to improve the stability of Pt because oxide species are key intermediates in the Pt dissolution process ${ }^{43}$, 45-46. Furthermore, the nitride NPs and nitrided CNTs exhibited better corrosion resistance than carbon black ${ }^{47-49}$, which suggests another reason for the catalyst's high stability. The ORR data shown in Figure 5d also demonstrate the catalyst's outstanding stability. The decay in ORR activity for $\mathrm{Ti}_{0.9} \mathrm{Cu}_{0.1} \mathrm{~N} @ P t / \mathrm{NCNTs}$ was less than 10\% after 10,000 cycles, compared with more than $50 \%$ for JM Pt/C. The durability of this catalyst thus exceeds even that of Pd@Pt core-shell catalysts ${ }^{10,13-14,50}$. To further investigate the structural stability of $\mathrm{Ti}_{0.9} \mathrm{Cu}_{0.1} \mathrm{~N} @ \mathrm{Pt} / \mathrm{NCNTs}$, we carried out HAADF/STEM imaging and EDS elemental mapping on the sample after the durability test (Figure S9). The results clearly show that the core-shell structure of the $\mathrm{Ti}_{0.9} \mathrm{Cu}_{0.1} \mathrm{~N} @ \mathrm{Pt} / \mathrm{CNTs}$ after long-term testing remained intact, demonstrating that the catalyst's excellent durability may be related to its structural stability. 

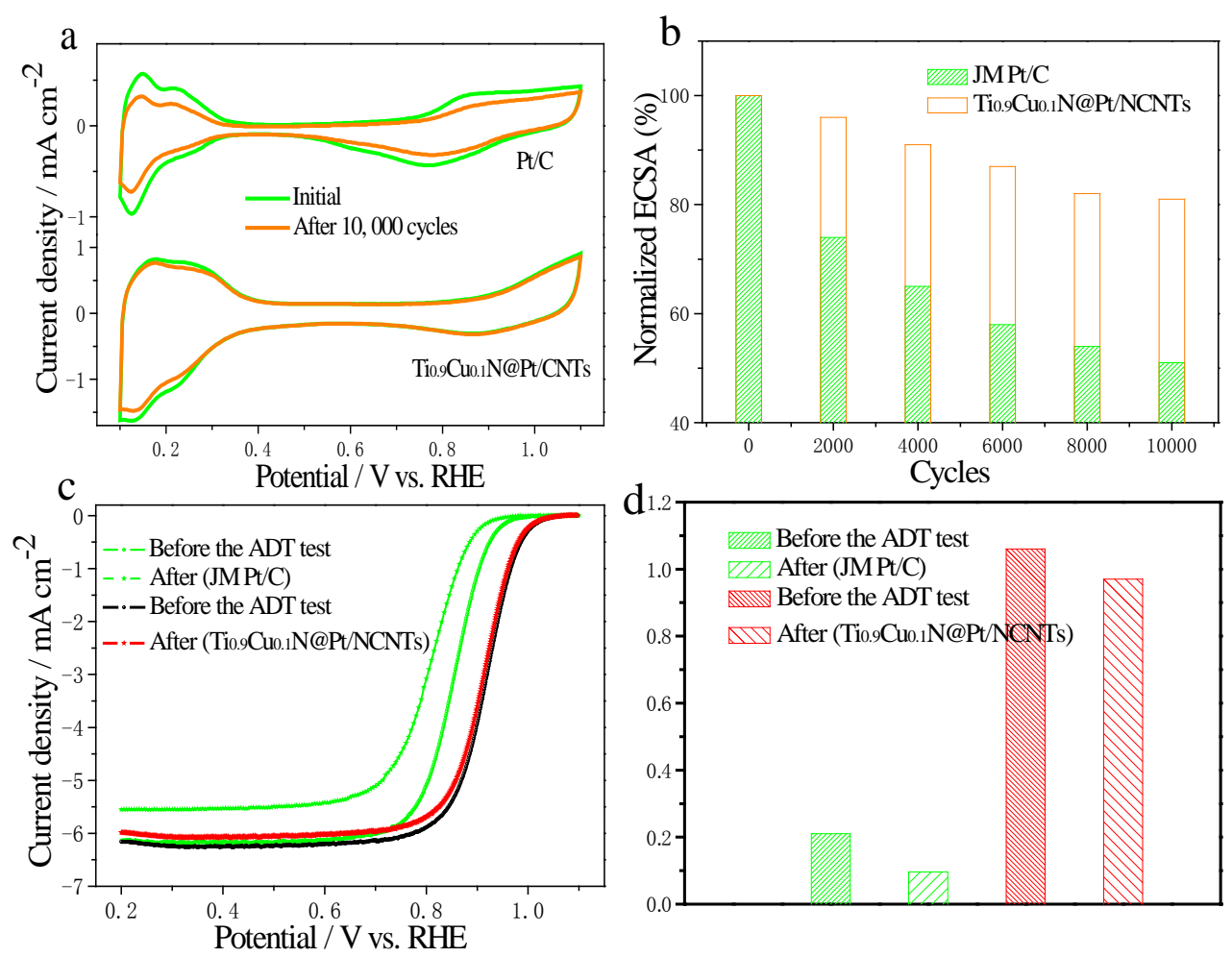

Figure 5. CV curves (a) and corresponding ECSA loss column diagrams (b) for JM Pt/C and $\mathrm{Ti}_{0.9} \mathrm{Cu}_{0.1} \mathrm{~N} @ \mathrm{Pt} / \mathrm{NCNTs}$ catalysts before and after accelerated durability testing (10,000 CVs). ORR polarization curves (c) and corresponding Pt mass activities columns (d) of JM Pt/C and $\mathrm{Ti}_{0.9} \mathrm{Cu}_{0.1} \mathrm{~N} @ \mathrm{Pt} / \mathrm{NCNTs}$.

\section{Conclusions}

In summary, we have developed a novel nitride-based low-Pt catalyst that has outstanding ORR activity and stability, prepared by depositing an ultra-thin Pt layer on welldispersed titanium copper nitride NPs that were supported on NCNTs. The Pt mass activity of the catalyst towards the ORR was five times higher than that of commercial $\mathrm{Pt} / \mathrm{C}$, and the catalyst exhibited far higher stability than Pt/C. It was found that doping the nitride core with $\mathrm{Cu}$ could significantly enhance the catalyst's performance. Compared with core-shell catalysts containing precious-metal NPs as the core, such as Pd@Pt/C, our nitride-core 
catalyst exhibited entirely comparable or slightly higher Pt mass activity, much higher PGM mass activity, and better stability/durability at much lower cost (the cost of $\mathrm{TiN} / \mathrm{Ti}_{0.9} \mathrm{Cu}_{0.1} \mathrm{~N}$ is almost negligible compared with that of $\mathrm{Pd}$ or $\mathrm{Au}$ ). This work represents a major breakthrough in the development of low-Pt core-shell catalysts and may provide a new pathway for generating low-cost fuel cell catalysts with excellent electrocatalytic activity and stability.

\section{ASSOCIATED CONTENT}

Supporting Information

Detailed characterization results, and additional electrochemical data. This material is available free of charge via the Internet at http://pubs.acs.org.

\section{AUTHOR INFORMATION}

Corresponding Authors

chsjliao@scut.edu.cn

adzic@bnl.gov

\section{Notes}

The authors declare no competing financial interest.

\section{Acknowledgements}

This work was supported by the National Science Foundation of China (NSFC Project Nos. 21276098, 21476088, 51302091, U1301245), the Ministry of Science and Technology of China (Project No. 2012AA053402), the Guangdong Natural Science Foundation (Project No. S2012020011061), and the Department of Education of Guangdong Province (Project No. 2013CXZDA003). 


\section{References}

(1). Xia, B. Y.; Wan Theng, N.; Wu, H. B.; Wang, X.; Lou, X. W., Angew. Chem. Int. Ed. 2012, 51, 7213-7216.

(2). He, D. S.; He, D.; Wang, J.; Lin, Y.; Yin, P.; Hong, X.; Wu, Y.; Li, Y., J. Am. Chem. Soc. 2016, 138, 1494-1497.

(3). Lim, B.; Jiang, M.; Camargo, P. H.; Cho, E. C.; Tao, J.; Lu, X.; Zhu, Y.; Xia, Y., Science 2009, 324, 1302-1305.

(4). Huang, X.; Zhao, Z.; Cao, L.; Chen, Y.; Zhu, E.; Lin, Z.; Li, M.; Yan, A.; Zettl, A.; Wang, Y. M.; Duan, X.; Mueller, T.; Huang, Y., Science 2015, 348, 1230-1234.

(5). Wang, C.; Chi, M.; Wang, G.; van der Vliet, D.; Li, D.; More, K.; Wang, H.-H.; Schlueter, J. A.; Markovic, N. M.; Stamenkovic, V. R., Adv. Funct. Mater. 2011, 21, 147-152.

(6). Cui, C.; Gan, L.; Heggen, M.; Rudi, S.; Strasser, P., Nat. Mater. 2013, 12, 765-771.

(7). Mayrhofer, K. J. J.; Hartl, K.; Juhart, V.; Arenz, M., J. Am. Chem. Soc. 2009, 131, 16348-16349.

(8). Gan, L.; Heggen, M.; O'Malley, R.; Theobald, B.; Strasser, P., Nano Lett. 2013, 13, 1131-1138.

(9). Zhao, X.; Chen, S.; Fang, Z.; Ding, J.; Sang, W.; Wang, Y.; Zhao, J.; Peng, Z.; Zeng, J., J. Am. Chem. Soc. 2015, 137, 2804-2807.

(10). Wang, X.; Choi, S. I.; Roling, L. T.; Luo, M.; Ma, C.; Zhang, L.; Chi, M.; Liu, J.; Xie, Z.; Herron, J. A.; Mavrikakis, M.; Xia, Y., Nat. Commun. 2015, 6, 7594.

(11). Sasaki, K.; Naohara, H.; Choi, Y.; Cai, Y.; Chen, W. F.; Liu, P.; Adzic, R. R., Nat. Commun. 2012, 3, 1115.

(12). Guo, S.; Zhang, S.; Su, D.; Sun, S., J. Am. Chem. Soc. 2009, 131 2013, 135, 1387913884.

(13). Park, J.; Zhang, L.; Choi, S.-I.; Roling, L. T.; Lu, N.; Herron, J. A.; Xie, S.; Wang, J.; Kim, M. J.; Mavrikakis, M.; Xia, Y., Acs Nano 2015, 9, $2635-2647$.

(14). Xie, S.; Choi, S. I.; Lu, N.; Roling, L. T.; Herron, J. A.; Zhang, L.; Park, J.; Wang, J.; Kim, M. J.; Xie, Z.; Mavrikakis, M.; Xia, Y., Nano Lett. 2014, 14, 3570-3576.

(15). Choi, S. I.; Xie, S.; Shao, M.; Odell, J. H.; Lu, N.; Peng, H. C.; Protsailo, L.; Guerrero, S.; Park, J.; Xia, X.; Wang, J.; Kim, M. J.; Xia, Y., Nano Lett. 2013, 13, 3420-3425.

(16). Li, H. H.; Ma, S. Y.; Fu, Q. Q.; Liu, X. J.; Wu, L.; Yu, S. H., J. Am. Chem. Soc. 2009, 131 2015, 137, 7862-7868.

(17). Tian, X.; Luo, J.; Nan, H.; Zou, H.; Chen, R.; Shu, T.; Li, X.; Li, Y.; Song, H.; Liao, S.; Adzic, R. R., J. Am. Chem. Soc. 2009, 131 2016, 138, 1575-1583.

(18). Choi, R.; Choi, S. I.; Choi, C. H.; Nam, K. M.; Woo, S. I.; Park, J. T.; Han, S. W., Chem. 2013, 19, 8190-8198.

(19). Wang, G.; Huang, B.; Xiao, L.; Ren, Z.; Chen, H.; Wang, D.; Abruna, H. D.; Lu, J.; Zhuang, L., J. Am. Chem. Soc. 2009, 131 2014, 136, 9643-9649.

(20). Chen, D.; Li, Y.; Liao, S.; Su, D.; Song, H.; Li, Y.; Yang, L.; Li, C., Sci. Rep. 2015, 5.

(21). Dang, D.; Liao, S.; Luo, F.; Hou, S.; Song, H.; Huang, P., J. Power Sources 2014, 260, 27-33.

(22). Chen, D.; Chen, R.; Dang, D.; Shu, T.; Peng, H.; Liao, S., Electrochem. Commun. 2014, 46, 115-119.

(23). Dang, D.; Zou, H.; Xiong, Z. a.; Hou, S.; Shu, T.; Nan, H.; Zeng, X.; Zeng, J.; Liao, S., ACS Catal. 2015, 5, 4318-4324.

(24). Tian, X.; Luo, J.; Nan, H.; Fu, Z.; Zeng, J.; Liao, S., J. Mater. Chem. A 2015, 3, 16801-16809.

(25). Dong, Y.; Wu, Y.; Liu, M.; Li, J., ChemSusChem 2013, 6, 2016-2021.

(26). Pan, Z.; Xiao, Y.; Fu, Z.; Zhan, G.; Wu, S.; Xiao, C.; Hu, G.; Wei, Z., J. Mater. Chem. A 2014, 2, 13966-13975. 
(27). Nan, H.; Tian, X.; Luo, J.; Dang, D.; Chen, R.; Liu, L.; Li, X.; Zeng, J.; Liao, S., J. Mater. Chem. A 2016, 4, 847-855.

(28). Nan, H.; Tian, X.; Yang, L.; Shu, T.; Song, H.; Liao, S., J. Nanomater. 2015.

(29). Li, H.; Yao, R.; Wang, D.; He, J.; Li, M.; Song, Y., The J. Phys. Chem. C 2015, 119, 4052-4061.

(30). Zhang, L.; Roling, L. T.; Wang, X.; Vara, M.; Chi, M.; Liu, J.; Choi, S.-I.; Park, J.; Herron, J. A.; Xie, Z.; Mavrikakis, M.; Xia, Y., Science 2015, 349, 412-416.

(31). Huang, Z.; Raciti, D.; Yu, S.; Zhang, L.; Deng, L.; He, J.; Liu, Y.; Khashab, N. M.; Wang, C.; Gong, J.; Nie, Z., J. Am. Chem. Soc. 2016, 138, 6332-6335.

(32). Xiao, Y.; Zhan, G.; Fu, Z.; Pan, Z.; Xiao, C.; Wu, S.; Chen, C.; Hu, G.; Wei, Z., J. Power Sources 2015, 284, 296-304.

(33). Ho, V. T.; Pan, C. J.; Rick, J.; Su, W. N.; Hwang, B. J., J. Am. Chem. Soc. 2011, 133, 11716-11724.

(34). Greeley, J.; Stephens, I. E. L.; Bondarenko, A. S.; Johansson, T. P.; Hansen, H. A.; Jaramillo, T. F.; Rossmeisl, J.; Chorkendorff, I.; Norskov, J. K., Nat. Chem. 2009, 1, 552-556.

(35). Stamenkovic, V.; Mun, B. S.; Mayrhofer, K. J. J.; Ross, P. N.; Markovic, N. M.; Rossmeisl, J.; Greeley, J.; Nørskov, J. K., Angew. Chem. Int. Ed. 2006, 118, 2963-2967.

(36). Strasser, P.; Koh, S.; Anniyev, T.; Greeley, J.; More, K.; Yu, C.; Liu, Z.; Kaya, S.; Nordlund, D.; Ogasawara, H.; Toney, M. F.; Nilsson, A., Nat. Chem. 2010, 2, 454-460.

(37). Lima, F. H. B.; Zhang, J.; Shao, M. H.; Sasaki, K.; Vukmirovic, M. B.; Ticianelli, E. A.; Adzic, R. R., J. Phys. Chem. C 2007, 111, 404-410.

(38). Adzic, R. R.; Zhang, J.; Sasaki, K.; Vukmirovic, M. B.; Shao, M.; Wang, J. X.; Nilekar, A. U.; Mavrikakis, M.; Valerio, J. A.; Uribe, F., Top. Catal. 2007, 46, 249-262.

(39). Hwang, S. J.; Kim, S.-K.; Lee, J.-G.; Lee, S.-C.; Jang, J. H.; Kim, P.; Lim, T.-H.; Sung, Y.-E.; Yoo, S. J., J. Am. Chem. Soc. 2012, 134, 19508-19511.

(40). Norskov, J. K.; Rossmeisl, J.; Logadottir, A.; Lindqvist, L.; Kitchin, J. R.; Bligaard, T.; Jonsson, H., J. Phys. Chem. B 2004, 108, 17886-17892.

(41). Peng, H.; Liu, F.; Liu, X.; Liao, S.; You, C.; Tian, X.; Nan, H.; Luo, F.; Song, H.; Fu, Z.; Huang, P., ACS Catal. 2014, 4, 3797-3805.

(42). Zhang, J.; Qu, L.; Shi, G.; Liu, J.; Chen, J.; Dai, L., Angew. Chem. Int. Ed. 2016, 55, 2230-2234.

(43). Liu, Y.; Mustain, W. E., J. Am. Chem. Soc. 2009, 131 2013, 135, 530-533.

(44). Kuttiyiel, K. A.; Sasaki, K.; Choi, Y.; Su, D.; Liu, P.; Adzic, R. R., Nano Lett. 2012, 12, 6266-6271.

(45). Yang, S.; Chung, D. Y.; Tak, Y. J.; Kim, J.; Han, H.; Yu, J. S.; Soon, A.; Sung, Y. E.; Lee, H., Appl. Catal. B: Environ. 2015, 174, 35-42.

(46). Zhang, Y.; Chen, S.; Wang, Y.; Ding, W.; Wu, R.; Li, L.; Qi, X.; Wei, Z., J. Power Sources 2015, 273, 62-69.

(47). Li, Y.; Zhong, G.; Yu, H.; Wang, H.; Peng, F., Phys. Chem. Chem. Phys. 2015, 17, 21950-21959.

(48). Wang, X.; Li, W.; Chen, Z.; Waje, M.; Yan, Y., J. Power Sources 2006, 158, 154-159.

(49). Nagaiah, T. C.; Kundu, S.; Bron, M.; Muhler, M.; Schuhmann, W., Electrochem. Commun. 2010, 12, 338-341.

(50). Wang, X.; Vara, M.; Luo, M.; Huang, H.; Ruditskiy, A.; Park, J.; Bao, S.; Liu, J.; Howe, J.; Chi, M.; Xie, Z.; Xia, Y., J. Am. Chem. Soc. 2009, 131 2015, 137, 15036-15042. 